\title{
Resistencia cristiana y esperanza profética. Lectura del Apecalipsis de Juan desde las víctimas
}

Xavier Alegre,

San Cugat de? ' allés, Barcelona, Centro de Reflexión Teológica, San Salvador.

\section{Introducción}

El Apocalipsis es, sin duda, un libro difícil y controvertido. Lo fue ya desde los comienzos. Muchas iglesias tardaron bastante tiempo en aceptarlo dentro del canon de los libros insphrados por Dios. Les parecía, entre otras cosas, demasiado violento, para poder ser realmente cristiano.

Para muchas cristianas y cristianos, sobre todo para los que viven en los grupos que solemos denominar sectas, es un libro terrible y amenazante, que anuncia la cercanía y las desgracias que acompañarán el fin del mundo. Para otros, en cambio - y pienso en las comunidades populares de El Salvador (donde he explicado más veces el Apocalipsis) - es un libro de esperanza, un libro que incita a la resistencia cristiana frente a los imperios opresores de turno. En todo caso, está lleno de tantas y tan complicadas visiones, que no suele haber mucho ánimo para leerlo (y menos para predicarlo).

La lesis que voy a exponer en este artículo es la siguiente. El Apocalipsis es un libro eminentemente histórico, pero habla de una historia que es vista en dos dimensiones que se complementan. Es algo así como lo que ocurría en los "autos sacramentales" medievales (piénsese en Calderón de la Barca). Por un lado, el autor considera la dimensión visible y empirica (Juan la llama la "tierra"). Y, por otro, existe una dimensión profunda y trascendente (Juan la llama el "cielo").

La convicción del autor es que Dios y el Mesías resucitado actúan en nuestra historia. Lo hacen liberando de la opresión y de la muerte y ayudando a consIruir un mundo alternativo. Es un mundo alternativo y jusio (en el que se ha erradicado la pobreza) que Dios, ya en el Antiguo Testamento, se había pro- 
puesto construir con el pueblo de lsrael (ver Dt 15, 1ss; Lv 25; Hech 2, 42-47). Pues la utopía del Apocalipsis no se realiza más allá de la historia, sino más allá de la opresión y de la muerte, en un mundo nuevo, que ya empieza a aparecer, en este mundo desde que Dios resucitó a Jesús.

\section{Cómo leer el Apocalipsis}

\subsection{Qué dice el Apocalipsis de sí mismo}

Detrás de sus visiones, a veces difíciles y complicadas, que a primeta vista parecen ofrecer un vídeo de los acontecimientos del fin del mundo - lo que puede provocar, fácilmente, el miedo de los leclores (una visión que, como vamos a ver, resulta lotalmente equivocada) - descubrimos que lo que el libro pretende, en lo más hondo, es "mantener viva la memoria de los mártires' y ponerla a producir", como suele decir Jon Sobrino, a propósito de los mártires salvadoreños.

Sobre todo quiere que se mantenga viva y perenne la memoria del primer mártir, el Cordero degollado (Ap 5, 6.12) ${ }^{2}$ que, resucitando (Ap 12, 4-5; véase también 5,6 ) ha vencido definitivamente al mal (simbolizado por Satanás y sus acólitos, las dos bestias que aparecen en Ap 12-13).

A este propósito, lo primero que podemos afimar es lo siguiente: Juan escribe su obra para subrayar que el triunfo de Jesús sobre la muerte y sus aliados es lo que ha posibilitado al pueblo cristiano, incluso en medio de la persecución más sangrienta, participar de la vicloria del Mesías y mantenerse fiel a su proyecto del reino, aun al precio de la propia vida. Pues para Juan la resurrección de Jesús es el hecho central que transforma toda la historia, una historia que, como vamos a ver, ha sido y sigue siendo muy conflictiva.

En este sentido, el Apocalipsis es - como voy a procurar mostrar- un escrito de resistencia, escrito por "los militantes (los guerrilleros) de la fe" (los profetas) y dirigido contra el imperio romano que persigue, oprime y asesina al pueblo (cristiano), empobrecido por no doblegarse ante sus valores. Juan quiere que tengamos esto bien presente cuando escribe: " $Y$ hace que todos, pequeños y grandes, ricos y pobres, libres y esclavos, se hagan uno marca en la mano derecha o en la frente, y que nadie pueda comprar nada ni vender, sino el que lleve la marca con el nombre de la Bestia o con la cifra de su nombre" (Ap 13, 16-17).

1. La comunidad del Apocalipsis es una comunidad perseguida por el imperio tomano y cuenta entre sus filas con numerosos mártires, como podemos ver por Ap 2, 13; 6, 9 $11 ; 7,9-17 ; 11,7-10 ; 13,15 ; 16,5-6 ; 17,6 ; 18,24 ; 20,4$.

2. Véasc lambićn 12,11, donde Juan recuerda a los crislianos que ellos vencieron al Diablo gracias a la sangre del Cordero. 
Por eso es tan importante para el autor mantener viva la memoria del Primer Mártir y ponerla a producir. Porque con su cruz (víctima también él del poder opresor del imperio) y su resurrección, Jesús se ha convertido para la comunidad en "una Buena Nueva (evangelio) eterna" (Ap 14,6), ya que fundamenta la fe y la esperanza (contra toda esperanza, desde la "lógica humana") del pueblo cristiano, el cual, de esla manera, es animado y exhortado a vivir los valores del reino, por los cuales Jesús dio su vida. Para el autor, sólo el Primer Mártir -y no Domiciano, por más que éste lo pretenda con su poder político, económico, social y religioso- es el auténtico señor de la historia y el único capaz de dar la luz y la fuerza que necesitan los cristianos para, en medio de las persecuciones, "guardar los mandamientos de Dios y mantener el testimonio de Jesús" (Ap 12, 17b).

Se trata, pues, de una obra subversiva para los poderes políticos injustos de la época, en la cual escribe el autor, porque desenmascara su mentira y advierte a los cristianos que no se dejen engañar por la propaganda religiosa del imperio romano (simbolizada por la Bestia de la tierra, en Ap 13, 11-17 o por su equivalente, el Falso Profeta, en Ap 20,10), que quiere engañar a los incautos, quienes se dejen seducir por su propaganda. En eslo se mueslra como creación e imagen del demonjo, "el padre de la mentira", como dice Juan 8, 44. Ésta es la razón por la cual esta obra ha de estar escrita en clave. Pues su mensaje cifrado intenta eludir una perseçución fácil, por parte del imperio romano.

\subsection{La situación que da pie a la literatura apocalíptica}

Para poder comprender mejor el tipo de literatura que encontramos en libros como el Apocalipsis es bueno que descubramos, ante todo, el motivo por el cual dicha literatura apocalíptica floreció en el mundo judío y cristiano, precisamente entre los siglos II a. C. y el I d. C. Es una literatura que floreció en tiempo de crisis. Pero no fue simplemente un tiempo de crisis en general, sino que fue una época en la cual tanto los judíos como los cristianos fueron perseguidos específicamente por su fe religiosa.

La persecución y el sufrimiento ya habian acompañado al pueblo de Dios antes del año 170 a. C. Incluso sus notables habían sido llevados al exilio por el imperio de tumo (primero Asiria y luego Babilonia), que había invadido y conquistado la tierra de Israel. Pero la causa de la persecución había sido, entonces, fundamentalmente político-económica. Sólo con el dominio de los reyes seléucidas -y de modo especial con Antíoco Epifanes (175-164 a. C), quien profanó conscientemente el templo de Jerusalén, erigiendo en él un altar a Zeus Olimpios-, los israelitas palparon en carne propia la persecución por motivos específicamente religiosos. Este hecho resultó tan impactante para el pueblo creyente de Israel, que provocó un despertar religioso y se concretó en una revolución amada -la de los hermanos macabeos (véase 1 y 2 Macabeos) - y en una literatura religiosa, que denominamos apocalíptica. 
En esta situación, la literatura apocalíptica quería ayudar al pueblo a mantener viva no sólo su identidad política, como pueblo, sino también su identidad religiosa, procurando alimentar su esperanza, en unos momentos en que ésla se veía seriamente amenazada y en los cuales una parte del pueblo creyente se dejaba seducir e incluso colaboraba con el imperio del norte (Siria) y sus acólitos dentro del mismo Israel.

Es precisamente en esla época cuando se escribe el único libro plenamente apocalíptico del Antiguo Testamento. Me refiero al libro de Daniel. Pero poco antes y después de Daniel se escribieron también un sinfín de obras, la mayoría de ellas muy populares, muchas de las cuales han sido divulgadas y traducidas a las lenguas modemas, en época reciente, contribuyendo así a que podamos interpretar mucho mejor los textos apocalípticos inspirados. Aunque tanto los judios, como después los cristianos, al fijar su canon las hayan considerado como apócrifas o no inspiradas - por lo menos en su mayoría-, por lo cual no han pasado a formar parte del canon biblico, sin embargo, nos consta que fueron obras muy populares, en aquel tiempo (no siempre se pensó que no fueran inspiradas, por ejemplo, en la carta de Judas se citan sin problemas la ascensión de Moisés y los libros de Henoc) e influyeron, sin duda en la teología de los primeros cristianos.

\subsection{Situación originaria del Apocalipsis de Juan}

Es en este contexto de persecución religiosa donde hay que situar el libro del Apocalipsis de Juan con el cual concluyen el Nuevo Testamento y la Biblia cristiana. La edición definiliva del Apocalipsis la sitúan los especialistas hacia mediados de los años 90 , cuando arreciaba la persecución del emperador Domiciano (81-96 d. C.) contra los cristianos. Antes del año 70 d. C. -fecha importante para el auge de los movimientos apocalípticos, por cuanto la conquista de Jerusalén por parte de los romanos y la destrucción del templo hicieron aumentar el sentimiento de crisis entre judíos y cristianos-, la actitud de éstos frente a los poderes políticos romanos estuvo marcada, más bien, por una actitud conciliadora y de lealtad hacia el imperio (véase, por ejemplo, Rom 13, 1-7).

Se era consciente de que Jesús había sido condenado a muerte por las autoridades romanas, pero, con todo, en los evangelios se presentaba este hecho como consecuencia de un error político de Pilatos, engañado por las autoridades judías. Se presentaba así porque, de entrada, se intentaba evitar el conflicto con la autoridad política que dominaba totalmente "la tierra conocida", en el mundo neotestamentario. Un conflicto político hubiera dificultado la misión cristiana en un mundo, en el cual el imperio romano era el dueño y señor absoluto. Incluso la persecución por parte de Nerón fue vista, más bien, como un hecho aislado, debido a la locura de un emperador concreto.

Pero la situación - por lo menos para las iglesias del profeta Juan-cambió bajo Domiciano. En su reinado, buena parte de la Iglesia choco con el poder 
totalitario romano, tanto en su dimensión civil como en la religiosa. Pues Domiciano, para dar solidez y unidad al imperio, exigía el culto y la adoración a su persona. Este culto era el signo y el distintivo del buen ciudadano que quisiera "hacer carrera", la condición imprescindible para poder llevar a cabo una existencia exitosa, política y económicamente. No se trataba de un conflicto anecdótico. Era un conflicto de principios. De ello toma conciencia clara el autor del Apocalipsis. Escribe su obra para desenmascarar el peligro que comportaban para su comunidad la propaganda y la opresión del imperio (la religión imperial resultó muy popular en la parte oriental, sobre todo en Asia Menor, lugar en el cual hay que ubicar, probablemente, el origen del Apocalipsis). Con su obra, Juan quiere ayudar también a su comunidad a resistir ante la persecución que, por lo menos a corto plazo, resultaba inevitable.

En este contexto conviene notar que el odio y la violencia de algunos textos son expresión de la siluación límite que está viviendo la comunidad. Juan parte de esta realidad, sin disimularla. Por ello recoge estos sentimientos "naturales" de odio para provocar en su comunidad una cátarsis, es decir, un desahogo y una purificación de eslos sentimientos, transformando el odio hacia el imperio en conciencia de la propia vocación e identidad. Por olro lado, la violencia que aparece en el Apocalipsis es más literaria que real. Pues el triunfador del cual se habla aquí es un Cordero degollado, es decir, un crucificado. Y los mártires, cuyo triunfo se proclama, derrotan a Satanás con su testimonio, como Jesús derrota a los pueblos con su "Palabra". En esto, el Apocalipsis se parece al Antiguo Testamenlo, el cual también parte de la realidad violenta que domina nuestro mundo y por eso no disimula la violencia en sus páginas, sino que intenta transformarla.

Pero, sobre todo, lo que el autor quiere impedir con su obra es que los fracasos aparentes en la resistencia frente a la prepotencia del imperio lleven a la comunidad a perder la esperanza, pues el imperio romano presentaba al emperador como el señor del mundo (véase Ap 13, 4-11) y exigía que se le diera culto, apoyándose para ello en su poder político y en las ideologías, incluida la propaganda religiosa, que lo sustentaban (véase Ap 13,11ss). El imperio exigía que se aceptaran, sin discusión, los valores (antivalores) que sostenían su poder.

Frente a esta pretensión, los cristianos tenían que reaccionar. Tenían que confesar, precisamente, todo lo contrario y desenmascarar — por fidelidad a su fe- los engaños que propalaba el imperio. A ello apunta la crítica del lujo, del orgullo y de la prepotencia económica y política que, en buena herencia profética (véase Is 1,$17 ; 2,12 s s ; 3,16-24 ; 5,8-9$, etc.), aparece en Apocalipsis 18, cuando canta, alborozado, la caída futura del imperio (véase también Ap 13, 16ss). Los cristianos se veían obligados a reaccionar así porque, para elios, sólo había un Dios, verdaderamente omnipotente, y un solo Señor, el Cordero degollado (véase Ap 17,14). Como es obvio, esta actitud crílica tenía que comportar para los cristianos una persecución violenta, por parte del Estado (Ap 12, 13; 13 , 
7) y, en ocasiones, el martirio (véase Ap 2,13, etc.). Pues como muy bien indica

C. Mesters, "el control de la policía era total; nadie podía escapar a su vigilancia $(13,6)$. Quien no apoyaba al régimen del imperio, no podía vender ni comprar nada $(13,17)$. El emperador era presentado como si fuera un nuevo Jesús. Hasta decían que él era un resucitado $(13,3.12 .14) "$.

No era, pues, fácil, en esta situación, mantenerse fiel a Jesús y a los principios y valores cristianos. Es por todo ello por lo que el profeta Juan (cfr. Ap 1, $3 ; 22,9)$ se decide a escribir esta obra a su comunidad, eligiendo para ello el género literario apocalíptico, familiar para ella y el más adecuado para responder, en buena tradición judía, a los retos que planteaba al cristianismo el imperio totalitario romano.

Resumiendo lo dicho hasta ahora, podemos constatar lo siguiente: 1) el Apocalipsis, que nace en tiempo de persecución recia para la lglesia, fomenta una espiritualidad de resistencia y promueve un mundo alternativo; 2) es un libro liberador, lleno de esperanza; 3) permite a la comunidad cristiana reconstruir su conciencia y su esperanza; 4) su utopía es historia y política.

\subsection{Finalidad del Apocalipsis}

En una época en la cual la Iglesia empieza a sufrir las consecuencias de una helenización excesiva, el autor se propone claramente uỉa reforma radical de la Iglesia (esto aparece muy claro en el primer septenario: el de las siete cartas).

Por lo que acabamos de ver ya podemos sospechar que lo que pretende el autor no es predecir el cómo y el cuándo del fin del mundo. Tampoco pretende asustar a la comunidad con la amenaza de un fin del mundo inminente y terrible. No respondería ello al talante de los hombres bíblicos inspirados.

Como todo apocalipsis de la época, el Apocalipsis es, más bien, un libro de circunstancias, preocupado por el aquí y el ahora que está viviendo la comunidad. Más que predecir cómo será el futuro, cosa que desconoce (recordemos que ya en el discurso apocalíptico de Jesús, que recoge el evangelio de Marcos, se nos advierte que ni a los ángeles del cielo, ni, tan siquiera, al Hijo ha revelado el Padre cuándo será el fin del mundo: véase Mc 13, 32; también Hech 1, 6-8 y Lc 21,8 , un texto, este último, que pone sobre aviso ante los falsos profetas cristianos, que dirán que "el tiempo está cerca"), lo que le preocupa al autor es la aclitud que debe tener el cristiano ante ciertas realidades terrenas que, de modo regular a lo largo de la historia, se manifiestan como amenazantes para la fe.

En este sentido, el Apocalipsis, sobre todo si se lee desde las víctimas, es una "literatura de combate", escrita, como decía al comienzo, por los militantes de la fe, quienes reflexionan sobre el modo cómo pueden resistir a las seducciones y asaltos del mundo (los poderes fácticos que se revelan como inhumanos, como "ídolos de muerte") y a las injusticias que padecen. 
En este supuesto, se comprenderá que la literatura apocalíptica utilice mucho el lenguaje simbólico críptico, pues quiere evitar que el imperio se entere bien de la gravedad denunciadora de sus texios $\mathrm{y}$, ante esta crítica, acentúe aún más su opresión".

De todos modos, el imperio opresor es cruel y goza de gran poder. Se lo pone muy difícil al teólogo apocalíptico. Por eso, la apocalíptica es también un tipo de literatura que parece tener una visión más pesimista sobre este mundo y sobre sus posibilidades de transformación. La historia no apunta a un final feliz intramundano. No se espera un progreso continuado. Se espera un mundo nuevo, más allá de la historia. Como nota J. Moltmann:

La historia es siempre lucha por el poder. Aquel que tiene el poder, se halla interesado en el progreso de la historia. Entiende el futuro como continuación y perfeccionamiento de su presente. Aquel que es impotente y se halla oprimido, no está interesado en la continuidad, ni en el perfeccionamiento de su historia de sufrimientos, sino únicamente en el pronto final de esa hisloria $y$ en un futuro altemativos.

Pero esta visión más bien desengañada del mundo no expresa toda la hondura del mensaje apocalíplico canónico. Pues es también un lipo de literatura que quiere fomentar, por activa y por pasiva, la esperanza, aunque parezca una esperanza "contra toda esperanza".

\subsection{La comunidad vive una situación muy dura}

Un periodista guatemalteco que recibió amenazas de muerte por parte de los escuadrones de la muerte, escribió lo siguiente:

Dicen que estoy "amenazado de muerte"... Tal vez. Sea de ello lo que fuere, estoy tranquilo. Porque si me matan, no me quitarán la vida. Me la llevaré conmigo, colgando sobre el hombro como un morral de pastor...

A quien se mata se le puede quitar todo previamente. Tal como se usa hoy, dicen: los dedos de las manos, la lengua, la cabeza... Se le puede quemar el cuerpo con cigarrillos, se le puede aserrar, partir, destrozar, hacer picadillo... Todo se le puede hacer, y quienes me lean, se conmoverán profundamente y con razón.

Yo no me conmuevo gran cosa. Porque, desde niño, Alguien sopló a mis oídos una verdad inconmovible que es, al mismo tiempo, una invilación a la

3. Una muestra típica de este lenguaje cifrado lo encontramos en Ap 13, 18: “iAqui se requiere sabiduría! Que el inteligente calcule la cifra de la Bestia; pues se trata de la cifra de un hombre. Su cifra es 666".

4. J. Moltmann, "Al linal, Dios», Concilium 277 (1998), pp. 648s. 
eternidad: "No teman a los que pueden matar el cuerpo, pero no pueden quitar la Vida".

La vida - la verdadera vida - se ha fortalecido en mí cuando, a través de Pierre Teilhard de Chardin, aprendí a leer el evangelio: el proceso de la resurrección empieza con la primera arruga que nos sale en la cara; con la primera mancha de vejez que aparece en nuestras manos; con la primera cana que sorprendemos en nuestra cabeza un día cualquiera, peinándonos; con el primer suspiro de nostalgia por un mundo que se deslíe y se aleja, de pronto, frente a nuestros ojos...

Así empieza la resurrección. Así empieza no eso tan incierto que algunos llaman "la otra vida", pero que en realidad no es la "otra vida", sino la vida "otra"...

Amenazados de muerte. ¿Y qué? Si así fuere, los perdono anticipadamente. Que mi cruz sea una perfecta geometría de amor, desde la que pueda seguir amando, hablando, escribiendo y haciendo sonreír, de vez en cuando, a todos mis hermanos los hombres.

Que estoy amenazado de muerte... Hay en la advertencia un error conceptual. Ni yo ni nadie estamos amenazados de muerte. Estamos amenazados de vida, amenazados de esperanza, amenazados de amor.

Cuando se escribió el Apocalipsis (o los apocalipsis sinóplicos: Mc 13 par), los cristianos podían pensar que no estaban "amenazados de resurrección", sino más bien "amenazados de desesperanza". La persecución que sufrían por parte del imperio romano se hacía sentir duramente. Muchos habían pagado ya su fidelidad a Cristo con el sufrimiento y la muerte, el martirio. $Y$ el imperio parecía invencible (¡tardó más de 300 años en caer!). Y era omnipresente. Por eso había que exhortar a las resistencia frente a él, aunque pareciera algo inútil y desesperado.

Lo primero que había que hacer en aquella situación era mostrar su debilidad, su fragilidad, para que no resultara absurda o alienante toda resistencia. El profeta Juan lo hace utilizando una imagen muy sugerente para el creyente, desde la experiencia del exilio en Babilonia. Aplica a Roma el calificativo despeclivo de "Babilonia" ( $c f$. Ap 18). Babilonia simboliza todo imperio cruel e injusto que, aunque parezca vencedor, acaba siendo vencido y destruido.

El primer imperativo de la esperanza consiste en no dejarse derrotar por la enorme fuerza de negatividad acumulada en Babilonia. Nuestra Babilonia hoy es el conjunto de exclusiones e insolidaridades, de comupciones y "pelotazos", de ansias de poder y de dominio. Frente a esa Babilonia, nos sentimos unas veces aplastados y otras fascinados.

5. J. García Roca , l. c., p. 64. 
Pero no basta con mostrar la debilidad del sistema dominante. Hay que alimentar también la esperanza, que los cristianos necesitan para recobrar el aliento. Es lo que pretende el Apocalipsis cuando canta, por activa y por pasiva, la victoria del Cordero, que aparecía como degollado, pero que estaba en pie (resucitado). Pues no se trata de una esperanza "barata". Ha sido comprada a un gran precio: la muerte de Jesús.

\section{Contenido del Apocalipsis}

\subsection{La fidelidad de Dios}

Si nos detenemos un poco más en el contenido del Apocalipsis, descubrimos que el hilo conductor de la reflexión (el leit motiv de la obra) es que Dios es fiel y misericordioso, liberador y protector del pobre y del oprimido. Se trata, por tanto, de un Dios que si en el pasado histórico de Israel se reveló con unas características y un estilo determinados, así se manifestaró también en el futuro.

En este sentido, nuestro autor, como los autores apocalípticos en general, sobre todo si son inspirados por Dios (me refiero, por tanto, a los bíblicos, que son para nosotros el criterio de discemimiento de toda inspiración que puede merecer el nombre de divina), es un fiel heredero de dos grandes corrientes del pensamiento bíblico, lasprofética y la sapiencial, que él ha sabido aplicar a la nueva situación que vive ahora el pueblo de Dios.

Como profeta que es, aunque parezca predecir el futuro, propiamente lo que pretende es ayudar a discernir los signos de los tiempos y a mostrar cómo hay que actuar en el presente, aunque ello comporte unas consecuencias políticas y económicas duras $y$, aparentemente, dichas opciones estén condenadas al fracaso -al menos según la lógica "humana". Si Juan insiste, aún más que en la profecía, en la actuación inminente y cierta de Dios -un Dios que, finalmente, "hará justicia"- se debe a que, como heredero también de las tradiciones apocalípticas y ante la crisis de fe que amenaza a su comunidad, quiere hacer palpable la acción de Dios que, en el momento actual, parece haberse olvidado de su pueblo.

Este aparente "olvido" es el que resuena en la queja de los mártires que encontramos en Apocalipsis 6, 9-11:

Cuando soltó el quinto sello, vi al pie del altar, con vida a los asesinados por proclamar la palabra de Dios y por el testimonio que mantenían; clamaban a grandes voces: "Tú el soberano, el santo y leal, ¿para cuándo dejas el juicio de los habitantes de la tierra y la venganza de nuestra sangre?". Dieron a cada uno una vestidura blanca y les dijeron que tuvieran calma todavía un poco, hasta que se completase el número de sus compañeros de servicio y hermanos suyos a quienes iban a malar como ellos. 
Pero el autor, desde su sabiduría creyente (biblica) sabe y proclama que Dios no puede haberse olvidado de su pueblo empobrecido y perseguido. Pues Dios sigue siendo el Señor de la historia que, si bien no le ha ahorrado a su pueblo la persecución y el martirio —el creyente sabe que ni siquiera bajó de la cruz a su propio Hijo (véase Mc 15, 29-32)-, sí se ha revelado siempre como salvador y dador de vida, no permitiendo jamás que la muerte triunfara definitivamente sobre la vida (no en vano el cristiano confiesa que Dios resucitó a Jesús como primicia de la nueva creación, que quiere irrumpir en nuestro mundo), como tampoco ha permitido ni permitirá que, a la larga, el mal triunfe sobre el bien. Por eso, Juan insiste en su libro en que los hechos "tienen que suceder pronto" (Ap 1,$1 ; 22,6.20$ ). No se trata, evidentemente, de un determinismo filosófico, que no sería bíblico. Lo que el autor quiere decir a sus oyentes es que los hechos que ocurren en el mundo están unidos y trabados en un plan de Dios que, visto a largo plazo (desde el cielo, la perspectiva de Dios), no tiene lagunas. Pero este plan no ha sido revelado a los seres humanos en todos sus detalles concretos, sino sólo en aquellos puntos de referencia y líneas generales fundamentales que permiten, con ayuda de un discemimiento creyente complejo (sapiencial), vislumbrar el sentido último (religioso) de la realidad que vive el creyente. Así éste puede hacer, adecuadamente, las opciones concretas que la situación exige.

Desde esta perspectiva global y hondamente creyente, se comprende que el autor se atreva a denominar su obra una Buena Noticia Eterna $(14,6)$. Se trata, efectivamente, de una Buena Noticia. Pero una Buena Noticia escrita por y para "los que tienen hambre y sed de justicia", pues sólo éslos pueden saber y creer que Dios los saciará, como había prometido Jesús (véase Mt 5, 6.10). Esta atmósfera claramente profética es la que lleva al autor a enmarcar su obra con unas bienaventuranzas (no es casual, como veremos luego, que haya un total de siete bienaventuranzas: véase Ap 1, 3 y 22, 14; véase lambién 14, 13; 16, 15; $19,9 ; 20,6 ; 22,7)$, la primera de las cuales subraya el valor del Apocalipsis: "Dichoso el que lea y los que escuchen las palabras de esta profecía y guarden lo escrilo en ella, porque el tiempo está cerca" (Ap 1, 3).

En todo caso, en el Apocalipsis, el autor no pretende damos, en absoluto, el vídeo de los últimos tiempos. Lo que pretende es des-velar el "velo" que oculta el sentido y el final de la historia, tal como éstos pueden ser anticipados a la luz de la fe. Pues con ello espera poder ayudar a los miembros de su comunidad a no dejarse engañar por las seducciones y amenazas del imperio romano.

\subsection{El significado de las cifras}

Al servicio de esta fe en la actuación del Dios fiel y misericordioso, liberador del pobre y del oprimido (a menudo es una fe que parece ir contra toda lógica meramente humana) está la sistematización que suele caracterizar la literatura apocalíptica. 
Las cifras simbólicas, que aparecen continuamente, la periodización de la historia en etapas, que se van repitiendo de modo regular y fijo, los motivos, que van resonando una y otra vez, quieren mostrar al lector-oyente los parámetros fijos de la historia, lo cual aparece muy claramente en la estructura concéntrica del Apocalipsis y en el paralelismo entre el segundo, el tercer y el cuarto septenario que, en el fondo, hablan de las mismas constantes históricas, pero cada vez desde una perspecliva distinta. Pues la historia humana, tal como la concibe el Apocalipsis, si bien avanza hacia un término de plenitud, revela, a la vez, determinadas constantes en las distintas etapas de la historia que serán válidas, por tanto, para la etapa en la cual viven el autor y su comunidads.

La estructura concéntrica ayuda a ver las coordenadas teológicas de la historia, pero sin caer en un etemo retomo de todas las cosas. Pues el autor, embebido como está del pensamiento bíblico, quiere mostrar también el progreso de la historia que avanza hacia su culminación, cuando Dios lo sea todo en todos.

El progreso se ve, por ejemplo, en que en los tres septenarios centrales, la gravedad de las plagas va en aumento o en el hecho de que en los septenarios segundo y tercero no se describe el contenido del séptimo sello y de la séptima trompeta, sino que se menciona tan sólo que se abre el sello y suena la trompeta, a fin de que el lector caiga en la cuenta de que el Apocalipsis no nos está hablando de momentosidistintos y sucesivos de la historia, sino de los mismos acontecimientos, pero vistos desde perspectivas distintas. Y toda la obra culmina en el juicio final (Ap 20,11-15) y en el cielo nuevo y la tierra nueva, que nos aguardan al final de la historia (Ap 21,1ss).

Con todo ello, Juan quiere afianzar en la comunidad la confianza en Dios, que es el que rige la hisloria con mano firme, a fin de que el lector confíe en que se realizarán las predicciones escalológicas que contiene el libro.

\section{El lenguaje criptico y simbólico}

El lenguaje críptico y simbólico es uno de los rasgos más específicos de la literatura apocalíptica. Los símbolos suelen estar tomados de los libros del Antiguo Testamento. En el Apocalipsis son, sobre todo, los libros del Exodo, de Ezequiel y de Daniel los más utilizados por el autor para sus afirmaciones y símbolos. La predilección por estos tres libros se debe a que precisamente en estos texlos aparece, con claridad meridiana, la intervención salvadora de Dios

6. La estructura del Apocalipsis y su significado los expliqué en mi articulo "L'estructura de l'Apocalipsi de Joan", Bulletl de l'ABC, Suplemenl 6 (1993) 44-55. La estructura muestra claramente cómo se pasa de la Iglersia militante aqul en la tierra (septenario de las cartas) a la lglesia triunfante en el cielo nuevo y la tierra nueva (séptima visión del quinto septenario: Ap 21, $1-22,5)$, a través de un historia terrena, que tiene su centro en la resurreción de Jesús (tercer septenario). 
en la historia. Pues en ellos se narran tres grandes acciones liberadoras de Dios a favor del pueblo de Israel: cuando era esclavo en Egipto, cuando estaba exiliado en Babilonia y cuando fue oprimido por los reyes seléucidas.

El lenguaje simbólico, además de ser más sugerente, tiene la ventaja de que, de alguna manera, universaliza el mensaje. Pues aunque los símbolos se estén refiriendo primariamente a una realidad que está viviendo el autor, el lenguaje simbólico ayuda a concienciar, sin embargo, que su mensaje es válido para lodas las épocas. Por lo menos es válido mientras Israel o la Iglesia sean peregrinas en esta tierra.

Esto aparece muy claro en algunos de los simbolismos utilizados por el Apocalipsis, tomados de la tradición profética y apocalíptica del Antiguo Testamento, aplicados allí a los imperios de tumo, que amenazaban al pueblo de Israel. Así, por ejemplo, si en Apocalipsis 17 y 18, el autor quiere hablar del imperio romano, que persigue a la comunidad, lo hará denominándola "la gran Babilonia, la madre de las rameras y de las abominaciones de la tierra" $(17,5)$, empleando unas imágenes que ya Isaías y Ezequiel habian utilizado para identificar las ciudades opresoras de Israel, sobre lodo Babilonia, que se convirtió en símbolo del mal y del peligro de idolatría para el pueblo creyente. Dentro de la misma línea puede denominarla también "la Bestia de la tierra" (Ap 13, 1ss) y la pintará diciendo que "se parecía a un leopardo, con las patas como de oso, y las fauces como fauces de león" (Ap 13,2), aplicándole así los símbolos que en Daniel 7, 4-6 se atribuían a los imperios babilonio, medo y persa. Así, subraya que el poder de Roma es como el de los tres imperios juntos. En todo caso, los símbolos con que pinta a la Bestia muestran, por un lado, que ella quiere hacer la competencia al Cordero degollado. Por otro lado, indican también que su poder, en el fondo, le viene del dragón o de la serpiente antigua, es decir, del diablo (véase 13, 2 junto con 12, 9 y todo el cap. 12). Y si la Bestia tiene siete cabezas (siete es el símbolo de plenitud, como hemos visto), es que con ello quiere ayudar al lector a identificar de qué realidad política está hablando, pues en Apocalipsis 17, 9 nos dirá que dichas cabezas simbolizan "siete colinas" (Roma era conocida en la Antigïedad como la ciudad de las siete colinas) o "siete emperadores", indicando en Apocalipsis 17, 10-11 que está aludiendo a Domiciano, a quien, por su crueldad y persecución de los cristianos, la comunidad aplica la leyenda que suponía que Nerón volvería a la vida y su reino sería aún más horroroso de lo que lo fue la primera vez.

Y por si al lector-oyente le podian quedar dudas de que se está refiriendo al emperador reinante, dirá, en Apocalipsis 13,18, “Aquí se requiere sabiduria! Que el inteligente calcule la cifra de la Bestia; pues se trata de la cifra de un hombre. Su cifra es 666". Con ello, el iniciado puede saber que se está refiriendo a Domiciano, el Nerón redivivo, pues la suma de las letras que componen el nombre de "Nerón César", si se toma su equivalencia en las letras hebreas, equivale a la cifra 666 . 
Con todo este simbolismo, Juan, además de dar la Buena Noticia al lector de que este imperio injusto caerá (véase Ap 16, 18 y la alegría con que canta su caída en Ap 18), le ayuda también a caer en la cuenta - a él y a los que vengan después de él- de que, cuando esto ocurra, no por ello debe bajar la guardia y la militancia cristiana. Pues cuando caiga Roma, Babilonia puede volver a resurgir: el monstruo, el dragón, renace sin cesar, en un mundo injusto - y la historia reciente de Centroamérica to muestra a cabalidad-, mientras no se haya hecho realidad el triunfo pleno de Dios (véase Ap 20,7-10) y no haya bajado a la tierra la Jerusalén celestial, el cielo nuevo y la tierra nueva (véase Ap 21, 1-22, 5), que Dios tiene prometidos para el fin de los tiempos. En esta perspectiva, por tanto, Juan le dice al cristiano que no debe ser ingenuo. Mientras el reino de Dios no se haya realizado plenamente en la tierra -y esto ocurrirá sólo al fin del mundo-, el conflicto entre el "mundo", en sentido juánico (véase Jn 1, 10; $3,19 \mathrm{~s} ; 15,18 \mathrm{ss}$, etc.) y el "evangelio" no es nunca un conflicto meramente anecdótico, sino que es un conflicto de principio.

En este sentido, el simbolismo resulta particularmente significativo, pues ayuda a concienciar que el mensaje del Apocalipsis es un mensaje válido para todas las épocas, mientras la Iglesia sea peregrina en esta tierra. Pues se trata de una tierra (estoy pensando en Monseñor Romero, en los mártires de la UCA y en las mayorías empobrecidas del tercer mundo, víctimas del hambre y de la violencia institucionalizåda) en la cual los "ídolos de muerte", que proféticamente denunció Juan, en Apocalipsis 18, siguen necesitando víctimas para poder saciar su voracidad y su lujo.

Las imágenes apocalipticas lo único que quieren desvelar es que estamos en el momento definitivo de la historia humana. Es el momento decisivo, en la crisis final, del discernimiento que revelará a cada uno el rostro de Dios: como salvador, si ha sido fiel al Cordero degollado, o como juez si, como la Roma imperial, ha perseguido a los cristianos y, en su orgullo, ha pretendido ser igual a Dios (véase Ap 13, 4-8), exigiendo que se le adore por medio de la propaganda, incluso religiosa, simbolizada por la Bestia de la tierra (véase Ap 13, 11-17) que, más adelante, es denominada el Falso Profeta (véase Ap 19, 20;20,10). De éste se afirma - iy sólo de éste en el Apocalipsis! (véase Ap 13, 13-14; 16, 14; $19,20$; véase también Mc $13,22 / \mathrm{Mt} 24,24)$ - que ha sido capaz de realizar milagros con el fin de engañar a los incautos que no han sabido descubrir el verdadero rostro de Satanás, el padre de la mentira (Jn 8, 44).

Por todo lo que acabamos de ver, podemos ahora entender mejor por qué el autor del Apocalipsis tenía interés en dar un mensaje "cifrado": su mensaje tenía que resultar demasiado revolucionario y subversivo pora el imperio romano. Las continuas alusiones al Antiguo Testamento (en principio desconocido para las fuerzas romanas de ocupación o de represión) en los símbolos del Apocalipsis tenían que resultar, de entrada, ininteligibles para las fuerzas represoras del imperio. En cambio, eran familiares para la comunidad de Juan. 


\subsection{Importancia de los ángeles y demonios}

En el marco de las claves de leclura del Apocalipsis, que estamos señalando, conviene notar también que todo el libro está poblado de ángeles y demonios, que participan activamente en la lucha entre el bien y el mal. Es un rasgo típico de la literatura apocalíplica. Pues sus autores "gozan" de una visión más bien pesimista de la historia, cosa comprensible si se tiene en cuenta la dura persecución que les ha tocado sufrir. Por ello se ven confrontados con un doble reto.

Por un lado, quieren alertar a la comunidad frente a las seducciones sutiles del imperio de turno, que quiere engañar - como procuran hacerlo todos los imperios- a sus súbditos, entre los cuales se cuentan las comunidades creyentes con su propaganda. Por ello pintan, un poco $\longrightarrow$ un mucho- de una manera dualista la realidad que está viviendo la comunidad, a fin de que quede bien claro de qué lado se ha de situar uno en esta lucha entre el bien y el mal, que tiene lugar aquí y ahora en el mundo.

Y, por otro lado, quieren salvar, a la vez, la trascendencia de Dios y su intervención en la historia. Pues para ellos, Dios es un ser absolutamente trascendente. Es el aspecto que las visiones de la sala del trono divino quieren subrayar en el Apocalipsis. Destacan la inaccesibilidad y la grandeza de Dios, quien lodo lo gobierna (véase Ap 4). Por este motivo, Dios sólo puede actuar en el mundo a través de sus enviados (los ángeles), evitando que las fuerzas del mal (los demonios) acaben triunfando sobre los creyentes. Esta concepción no resultaba nada sorprendente en la época, pues les parecía obvio que todo en el mundo (incluso los vientos, los ríos o las estrellas) estaba impulsado por ángeles.

\subsection{El carácter litúrgico}

Por último, quisiera subrayar un elemento significativo: el talante claramente litúrgico del Apocalipsis. Está lleno de himnos litúrgicos, unos himnos en los cuales se proclama, por activa y pasiva, que Dios (y Jesús) es el auténtico señor del mundo y de la comunidad, que ha lavado sus vestidos con la sangre del Cordero (véase Ap 7, 14). Estos himnos son como los cantos de resistencia de la comunidad -como ocurre, por ejemplo, en El Salvador, oprimido también por el imperio del norte y sus aliados, donde las comunidades populares cantaban (y cantan) los corridos de Monseñor Romero, de Rutilio Grande o del Padre Nacho. Una comunidad que no se cansa de proclamar que Jesús, y no Domiciano (o el déspola de tumo), es "el Señor". Son comunidades que cantan con alegría la venida futura del Cristo liberador, fuente de esperanza para la comunidad (véase Ap 22, 16-21). Y con estos cantos se animan a seguir resistiendo, "aunque es de noche".

El tono litúrgico de los textos comporta para la comunidad otra enseñanza que para Juan es importante. Le recuerda que las celebraciones litúrgicas son 
anticipaciones del final de la historia que, con la resurrección de Jesús, ha imumpido ya en nuestro mundo. Por otro lado, son también medios eficaces de la intervención de Dios en la historia, a la vez que una ayuda para movilizar al pueblo cristiano. Pues los cantos son un llamado a resistir y a contrarrestar las asechanzas del imperio con todos los medios posibles, entre los cuales destaca el culto, ya que en el Apocalipsis estamos muy lejos de las liturgias, a menudo alienantes, de muchos grupos pentecostalistas o carismáticos actuales.

Por otro lado, es un motivo típico de la apocalíptica que, en medio de la persecución, la oración es mós necesaria que nunca. Lo subraya también Lucas en el discurso apocalíptico, cuando ponc en boca de Jesús estas palabras: "estén en vela, pues, orando en todo tiempo para que tengan fuerza y escapen a todo lo que está para venir, y puedan estar en pie delanle del Hijo del hombre" (Lc 21, 36). La oración, por olro Jado, ayuda también a concienciar que la salvación definitiva es puro don gratuito de Dios.

\section{La lección central del Apocalipsis para la historia}

Todo lo que acabo de decir aparece muy claramente en el septenario de las trompetas. Es el septenario central del Apocalipsis. Por ello es el más desanollado, pues constituye el corazón de la revelación que Juan quiere comunicar a sus comunidades. Con el śmbolo de las trompetas, Juan llama a la movilización (cfr. Jr 4,$5 ; 1$ Co 14, 8) de los cristianos, en un momento decisivo de la historia. Las siete trompetas anuncian las desgracias que aguardan al mundo, si se cierra a la llamada de Dios a la conversión. En este sentido, las plagas anunciadas en las seis primeras trompetas indican, como Juan ha indicado ya en el septenario de los sellos, que los males del mundo no son fruto de la arbitrariedad o malevolencia de un Dios terrible, sino una llamada a la conversión. Por esto aquí se acrecientan las consecuencias negativas de las plagas con respecto al seplenario anterior, pero sin llegar a la totalidad que alcanzarán en el septenario siguiente, el de las copas, que representa la última llamada de Dios a la conversión.

\subsection{La vocación cristiana}

Las alusiones al Antiguo Testamento muestran que todo este septenario está inmerso en una atmós「era pascual. Ello viene confirmado también por el hecho de que antes de que suene la séptima trompeta, Juan interrumpe el relato para desarrollar (cfr. Ap 10, 1-11, 14) un amplio intermedio. En él, Juan indica al creyente cuál es su vocación cristiana, si tiene presente el significado fundamental de la resurrección de Jesús. Con la aparición, en Apocalipsis 10, del ángel majestuoso, que lleva en su mano el librito que Juan es invitado a comer (en una alusión clara a la vocación profética de Ezequiel: cfr. Ez 3, 3.14), el autor quiere hacer referencia a su vocación profética. Por eso, el ángel le indica que, una vez haya comido el librito, éste le resultará dulce y amargo a la vez: 
dulce, porque su predicación contendrá una Buena Noticia eterna (cfr. Ap 14, 6), que consiste en el triunfo de Dios, que en este septenario queda concretado en el anuncio pascual del triunfo de Jesús sobre Satanás, que será narrado, simbólicamente, en el segundo intermedio (cfr. Ap 12). Pero amargo también, pues Juan ha de anunciar el castigo a quienes se cierran al mensaje de Dios, lo cual le comportará persecución y, quizás, el martirio.

La descripción de la vocación profética de Juan ha preparado el Capílulo 11, en el cual se simboliza la situación que está viviendo la comunidad, destacando dos aspectos complementarios, que acompañan siempre la vida de las iglesias. En primer lugar, Juan recuerda que, aunque los sufrimientos de la comunidad puedan llevar a pensar lo contrario, de hecho, las iglesias están siempre protegidas por Dios. Esto es lo que expresa la orden, inspirada en Ezequiel 40, 1-5 y Zacarías 2, 5-9, de medir el santuario y el altar y a los que adoran en él (cfr. Ap $11,1)$. Y, en segundo lugar, que dicha protección no excluye que las iglesias puedan ser perseguidas y martirizadas por el imperio. Pero ello ocurrirá sólo durante un tiempo limitado (jtres años y medio!), como se expresa con la orden de que no mida el patio exterior del santuario, "porque ha sido entregado a los gentiles que pisolearán la Ciudad Santa cuarenta y dos meses" (Ap 11, 2).

A continuación, en Apocalipsis 11, 3-13, Juan desarrolla la vocación profética que han recibido todos los cristianos (cfr. Herh 2, 14-21). Ya Marcos había indicado, en un texto también apocalíptico, que antes del final escatológico de la historia, el evangelio debía ser predicado a todas las naciones (cfr. Mc 13,10 ), dando con ello una tarea a su iglesia, incluso después de la caída de Jerusalén, a la cual se alude en Marcos 13, 14ss, aunque ello le comportara persecuciones (cfr. Mc 13, 9-13). En el mismo sentido, Juan quiere subrayar a su comunidad que debe dar testimonio profético en el mundo anles de que suene la séptima trompeta. Por ello se subraya que son profetas (cfr. Ap 11, 3.6.10). No es obstáculo para esta interpretación el que sean descritos con unos rasgos que aluden a los dos grandes profetas del Antiguo Testamento, Elías y Moisés, cuyo retomo se esperaba para el fin de los tiempos (cfr. Dt 18,18; Ml 3,23), como puede verse por el hecho de que se afirma de ellos, por un lado, que "tienen poder de certar el cielo para que no caiga la lluvia" $(2 \operatorname{Re} 1,17)$ y, por otro, que tienen poder para desencadenar las plagas (cfr. Ex 7,$17 ; 11,10)$ sobre el mundo que no se convierte y les persigue (cfr. Ap 11,6).

Si estos textos se leen en el contexto en el cual los ha colocado Juan, se ve que lo que quiere indicar con ellos es que el testimonio profético cristiano es el cumplimiento de lo anunciado en el Antiguo Testamento, una idea muy familiar en el Apocalipsis. A la vez se les anuncia (como ya lo había hecho Jesús con sus discípulos según Jn 16, 1-4), que compartirán el destino de Jesús (ver Mc 8, 34), es decir, su muerte y resurrección, pues provocarán la oposición del mundo que llegará, incluso, a asesinarlos y se alegrará con su muerte (cfr. Ap 13, 7-10). 
Pero se les revela también que Dios no los dejará de su mano, incluso en esta vida (cfr. Ap 11,5), y que, pasado un tiempo breve, aparecerán, incluso a sus enemigos, como compartiendo la glorificación de Jesús (cfr. Ap 11, 11-13). En este marco, Juan quiere afimar, también, que con su testimonio, los profetas cristianos acelerarán la venida del reino de Dios. Por eso es tan importante para él que los cristianos cumplan con su misión de profetas.

Por otro lado, la noticia de que algunos se convertirán (cfr. Ap 11,13) es un mensaje de consolación para los que viven en medio del "segundo ay", es decir, en medio de las pruebas escatológicas, que está viviendo la comunidad (cfr. Ap $9,13-11,14)$ y que preparan el toque de la séptima trompeta La séptima trompeta anuncia el castigo definitivo de Dios contra el imperio romano y el acercamiento de los últimos tiempos.

Pero cuando suena la séptima trompeta, en Apocalipsis 11, 15a, Juan, como había ocurrido ya en el segundo septenario, no describe los resultados de dicho loque (es, una vez más, una manera de invitarnos a que leamos el siguiente septenario, el de las copas, como explicación, esta vez definitiva, de lo que se ha anunciado en este septenario), sino que deja resonar un cántico en el cielo ( $c f r$. Ap 11, 15b-19), que anticipa el triunfo final de Dios, quien va a hacer justicia, restableciendo su reinado ya aquí, en la tierra. No es casual que, precisamente en este lugar, Juan recuerde el motivo que subyace a toda la reflexión teológica del Apocalipsis: la fidelidad de Dios a la alianza que estableció con su pueblo.

\subsection{La lucha entre el dragón y la mujer (Ap 12-13)}

En este fragmento, Juan desvela (cfr. Ap 12) el trasfondo de la lucha a muerte, que enfrenta a los cristianos con el imperio. Lo primero que nos presenta es "una mujer" vestida de sol, con la luna bajo sus pies y una corona de doce estrellas (cfr. Ap 12,1). Esta mujer simboliza el pueblo de Dios y las doce estrellas representan las doce tribus de Israel, que va a ser reconstituido con la venida y triunfo del Mesías. Frente a la Mujer, que está a punto de dar a luz (cfr. Ap 12, 2), Juan sitúa a la Serpiente roja, que, por su color, sus cabezas (isiete!), sus cuernos (¡diez!) y sus diademas representa el poder demoníaco (en Ap 12, 9 se la identifica explícitamente con Satanás), quiere acabar con la Mujer y su descendencia, como lo intentó ya al comienzo de la creación (cfr. Gn 2-3).

Pero cuando "la Mujer dio a luz un Hijo varón, el que ha de regir a todas las naciones con cetro de hierro" (por la descripción se ve claro que se trata del Mesías) "su Hijo fue arrebatado hasta Dios y hasta su trono" (Ap 12,5), con lo cual el Diablo, que ha intentado devorarlo (véase Ap 12,4b), no sólo no consigue acabar con él, sino que va a sufrir las consecuencias, en buena ironía juánica, de esta elevación del Hijo a Dios. Con ello se ve claro que el autor, más que referirse al nacimiento del Mesías, está hablando, primariamente, con unas imágenes que nos resultan familiares por el cuarto evangelio, de la exaltación 
del Hijo. Como indica Charpentier, "la mujer simboliza al pueblo de Dios, a la Iglesia, que da nacimiento al mesías en el drama del calvario. Satanás, dertotado, se arroja contra los demás hijos de la mujer, contra todos los cristianos, y les hará la guerra durante todo el tiempo de la historia". Como ocurre en el cuarto evangelio, la cruz es vista como exaltación ( $c f r . \mathrm{Jn} 3,14 ; 8,28 ; 12,32 \mathrm{~s}$ ) y como trono, en el cual Jesús reina (cfr. Ap 12,5).

El fragmento siguiente (cfr. Ap 12, 7-12) saca las consecuencias de esta vicloria pascual y nos presenta la dimensión última de esta derrola del demonio con la imagen clásica (mítica) de la lucha entre Miguel, que está al frente de sus ángeles, y la Serpiente, que está también al frente de sus ángeles (caídos). Esto significa que con la exaltación de Jesús ha empezado ya el reinado del Cordero degollado. Ello implica que Salanás ha sido vencido y ha perdido su poder, lo cual queda simbolizado con el hecho de que es expulsado del cielo (una imagen que encontramos también en Lc 9, 18 y Jn 12, 31-32). Pero esto no significa que Satanás carezca ya de todo poder. Pues no hemos llegado aún a la plenitud del reino. Por eso, para prevenir al lector de las amenazas que para el cristiano comportan los "poderes del mal", muy activos en la tierra, Juan añade una advertencia en Apocalipsis 12, 12b: "iAy de la tierra y del mar! porque el Diablo ha bajado a ustedes rebosando furor, sabiendo que le queda poco tiempo". Con todo, también aquí hay una nota positiva. Pues,en medio de esta lucha, el pueblo cristiano sigue siendo protegido por Dios, como lo fue el pueblo de Israel en el desierlo (cfr. Ap 12, 13-16 con Ex 19, 4 y 14, 27ss). Pero ello no quila que ahora el demonio persiga, encamizadamenle, "a los que guardan los mandamientos de Dios y mantienen el testimonio de Jesús" (Ap 12, 17).

Con ello, Juan nos ha descifrado lo fundamental de las realidades más hondas, que configuran nuestra historia. Pero quiere clarificar aún más lo que acaba de decir, desenmascarando las fuerzas demoníacas que, basándose en la mentira, quieren engañar a los cristianos. Por eso, en una segunda parte de este largo intermedio (y preparado por Ap 12,18) pone al descubierto las potencias aliadas de Satanás aquí en la tierra y explica de qué recursos se valen para oprimir a la Iglesia.

Estas fuerzas del Mal están representadas por dos bestias. Por un lado, la Bestia del mar (cfr. Ap 13, 1-10), que simboliza la Roma omnipotente políticamente. Es como la encamación de todos los imperios totalitarios, como puede ver el lector iniciado en el Antiguo Testamento por el hecho de que en Apocalipsis 13, 2 se le aplica la descripción de los imperios enemigos del pueblo de Israel, que aparecen en Daniel 7, 4-6. Se Irata del imperio que, en su orgullo, se idoliza a sí mismo y martiriza a los cristianos, que no quieren adorarlo (cfr. Ap 13, 4-7). Y, por olro, desenmascara a la Bestia de la tierra (cfr. Ap 13, 11-17) que, más adelante (cfr. Ap 19, 20 y 20,10) es denominada "el falso Profeta". Es el símbolo de la propaganda religiosa ( $y$ de las ideologias), que están al 
servicio del imperio (cfr. Ap 13, 12-15) y son muy peligrosas, por cuanto utilizan su poder no sólo para engañar a los ingenuos, sino también para marginar, incluso económicamente, a todo el que no quiere adorar a la primera Bestia. En este sentido, el Dragón y sus dos acólitos, que son creatura e imagen de él, formando así una especie de trinidad satánica, que intenta emular a la trinidad divina, expresan el peligro que comporta para los cristianos un Estado totalitario y despótico, como el de Roma, en tiempo del emperador Domiciano (al que se alude en Ap 13,18), que quiere convertirse en ídolo y obligar a los cristianos a renunciar a sus valores para aceptar, en su lugar, los del imperio.

Y como la dureza de la persecución en la comunidad es notable y, por otro lado, parece que el poder del imperio es inconmovible (de hecho, lardó algo más de tres siglos en caer), Juan no quiere terminar este septenario sin que resuene en la liturgia celestial ( $c f r$. Ap 14, 1-5) el cántico triunfal de "los que siguen al Cordero a dondequiera que vaya, y han sido rescatados de entre los hombres como primicias para Dios y para el Cordero" (Ap 14, 4).

Con todo ello, el autor nos ha preparado para la lectura del cuarto seplenario, en el cual nos mostrará, ahora ya de modo definitivo, lo que le aguarda al imperio cruel, que no quiere convertirse y martiriza a los cristianos.

\subsection{Significado del cielo nuevo y de la tierra nueva (Ap 21, 1-22, 5)}

Cuando mira la realidad de este mundo, el apocalíptico tiene una mirada muy pesimista, como hemos visto.

Pero los apocalipsis biblicos no son escenarios pesimistas de la destrucción del mundo, que difundan el miedo y el tertor y quieran paralizar a las personas. Lejos de eso, mantienen la esperanza en la fidelidad de Dios a su creación, en medio de los horrores de la época. "Cuando empiecen a suceder estas cosas, cobren ánimo y levanten la cabeza, porque se acerca su liberación", se dice en Lucas 21,28 . La esperanza profética es esperanza en acción; la esperanza apocalíptica es una esperanza en medio del peligro, una esperanza que sabe aguantar el sufrimiento y que es paciente y perseverante: suceda lo que suceda, al final de todo se halla Dios. Es una doctrina de esperanza y no tiene nada que ver con las fantasías sobre la desirucción del mundo, proclamadas por los modernos profetas y los terroristas?.

El final del Apocalipsis muestra un aspecto que es esencial para la apocalíptica inspirada por Dios: que la esperanza cristiana es, fundamentalmente, un don (de Dios). El tono positivo con que termina el Apocalipsis es esencial a la revelación bíblica (que ha visto su obra que "desvela" la actuación de Dios en la historia como una "Buena Noticia etema" (Ap 14, 6). Como nota muy bien Moltmann":

7. Molımann, op. cit., pp. 654s.

8. Ibid., p. 6556. 
Según las tradiciones bíblicas, el comienzo de la historia del mundo no comienza con la caída en el pecado $y$, por eso, no termina tampoco con la destrucción del mundo. Comienza con la bendición original de la creación temporal y termina con la bienaventuranza de la creación eterna. La última palabra de Dios no es un juicio condenatorio, sino aquella palabra creadora: "He aquí que hago nuevas todas las cosas" (Ap 21,5$)$. Es el "nuevo cielo y la nueva tierra", después que habían desaparecido "el primer cielo y la primera tierra" (Ap 21,5). Todo lo que se representa como juicio universal y destrucción del mundo no es más que una etapa provisional para lo definitivo de la nueva creación.

Pueslo que la justicia de Dios es la base de un mundo etemo, que se halla en correspondencia con él, ese mundo lendrá que ser acrisolado primeramente en todo, mediante el juicio universal. Por eso, a la nueva creación de todas las cosas le precede, según la esperanza cristiana, el juicio universal. Pero esa justicia de Dios no es justicia punitiva y vindicativa, sino justicia creadora y justificante para las víclimas y los hacedores de la historia humana del mundo. Dios no viene para ejecutar, sino para enderezar y levantar.

De entre los textos finales del Apocalipsis, destacaré dos promesas, que son como su conclusión.

Vi enlonces un cielo nuevo y una tierra nueva, porque el primer cielo y la primera tierra habían desaparecido y el mar [isimboliza el mal!] ya no existía. Y vi bajar del cielo, de junto a Dios, a la ciudad santa, la nueva Jerusalén, ataviada como una novia que se adoma para su esposo. Y oí una voz potente que decía desde el trono: ésta es la morada de Dios con los hombres; él habitará con ellos y ellos serán su pueblo; Dios en persona estará con ellos y será su Dios. El enjugará las lágrimas de sus ojos, ya no habrá muerte ni luto ni llanto ni dolor, pues lo de antes ha pasado. $Y$ el que estaba sentado en el trono dijo: Todo lo hago nuevo (Ap 21, 1-5a).

Me mostró entonces el ángel el río de agua viva, luciente como el cristal, que salía del trono de Dios y del Cordero. A mitad de la calle de la ciudad, a cada lado del río crecía un árbol de la vida: da doce cosechas, una cada mes del año, y las hojas del árbol sirven de medicina a las naciones. Allí no habrá ya nada maldito. En la ciudad estará el trono de Dios y del Cordero, y sus servidores le prestarán servicio, lo verán cara a cara y llevarán su nombre en la frente. Noche no habrá más, ni necesitarán luz de lámpara o del sol, porque el Señor Dios irradiará luz sobre ellos y serán reyes por los siglos de los siglos (Ap 22, 1-5).

El Apocalipsis termina con el cielo nuevo y la tierra nueva, con la nueva Jerusalén bajada del cielo, descrilos con unos rasgos que pueden alimentar el imaginario cristiano y la esperanza del creyente. 
No es, entonces, casual que su lectura haya alimentado tantas veces la fe y la esperanza de las comunidades cristianas perseguidas, que siempre han sintonizado de modo especial con su mensaje. Esta ha sido al menos mi experiencia con las comunidades de El Salvador, que han vivido en carne propia, en tiempos recientes, la persecución del imperio (norteamericano) y de sus aliados, quienes adoran su imagen y sus antivalores.

\section{Conclusión}

A modo de ejemplo, quisiera concluir con un texto que escribió uno de mis alumnos de la UCA al final de un trabajo escolar sobre el Apocalipsis, imitando su estilo:

Yo, Juan, ciudadano y hermano de ustedes, Pedro, Pablo, María y José, participo de la tribulación y angustia que sufre mi pueblo. Estaba orando, cuando oí que un monstruo daba voces que venían de los cuatro puntos cardinales. Eran voces penetrantes e insoportables que golpeaban la inocencia de la gente, sacudiéndola con violencia.

Como un viento recio, la voz venía del norte, traspasando las fronteras. Me dijo: "soy el poder económico. Después de ir a muchos lugares he venido a li para decirte: mi misión y mi responsabilidad es muy grande. De mí depende el desarrollo de lôs pueblos y la distribución de las riquezas. Yo tengo la llave de la abundancia y de la escasez. Yo soy el responsable de que el pueblo tenga prosperidad y bienestar o tenga miseria y dolor. Haz lo que le mando y te daré lo que quieras".

Después de esto vi que el monstruo sopló por el sur y del mar salió una mano gigante con una espada reluciente, con la cual azotó la tierra y a sus habitantes. Y me dijo: "Yo soy el poder militar y tengo por misión guardar la paz y el orden, y hacer prevalecer la justicia y el derecho y respetar la vida. Si inclinas la cabeza, yo te protegeré".

La voz que vino del occidente llegó sutilmente. $Y$ ofreciéndome una manzana, me dijo: "Yo soy el poder político. Mi misión es formar gobiemos y sostenerlos, cambiarlos para mejorar o para empeorar. Por esto todos esperan en mí. Si me sirves, te daré un lugar junto a mí".

La voz del oriente venía hacia mí, cuando fue atravesada por el sol. Esa voz se convirtió en pequeñas voces y me dijo: "Yo soy el poder de la fe. Tengo por misión despertar o adormecer la conciencia de Juan, Pedro, Pablo, María y José; hacer que su vida tenga sentido o que la pierda. Sin mí, los otros poderes valen poco. Por esto están siempre conmigo y me usan para su fin. Mira que somos muchas voces. Usa tu discemimiento y encontrarás un tesoro escondido. El que tiene oídos, que entienda". 
Después de esto vi una gran muchedumbre de hombres, mujeres y niños, quienes caminaban con una cruz en el pecho, librando una batalla contra la muerte y queriendo alcanzar una paloma blanca.

Estando afligido y aterrorizado por los males que vi en mi tierra, busqué el tesoro escondido y encontré una caja muy blanca que en su interior tenía escritas las palabras "justicia, paz, liberación, fratemidad, esperanza y vida". De su interior salió una luz intensa, que cegó y destruyó al monstruo de las cuatro voces.

La luz se convirtió en río cristalino, el cual regaba la tierra. Y comenzaron a salir del corazón de la tierra innumerables casas. Los árboles saltaban de alegría. Y vi que del cielo cayó un pan muy grande y una copa semejante, rebalsando de alegría. Y lloré por última vez y reí con ganas, porque alrededor del pan y de la copa estaban Juan, Pedro, Pablo, María y José. 